\title{
The age U-shape in Europe: The protective role of partnership
}

\author{
Andrew E. Clark ${ }^{1}$, Hippolyte d'Albis ${ }^{1, *}$ and Angela Greulich ${ }^{2}$
}

\section{Abstract}

In this study, we ask whether the U-shaped relationship between life satisfaction and age is flatter for individuals who are partnered. An analysis of cross-sectional EU-SILC data indicates that the decline in life satisfaction from the teens to the fifties is almost four times larger for non-partnered than for partnered individuals, whose life satisfaction essentially follows a slight downward trajectory with age. However, the same analysis applied to three panel datasets (BHPS, SOEP and HILDA) reveals a U-shape for both groups, albeit somewhat flatter for the partnered than for the non-partnered individuals. We suggest that the difference between the cross-sectional and the panel results reflects compositional effects: i.e., there is a significant shift of the relatively dissatisfied out of marriage in mid-life. These compositional effects tend to flatten the U-shape in age for the partnered individuals in the cross-sectional data.

Keywords: life satisfaction; life cycle; partnership; marriage

\section{Introduction}

In the literature on the relationship between subjective well-being and age, one of the recurrent themes has been the shape of this relationship. While some contributions on this this topic have suggested that the relationship is essentially flat (for example, Kassenböhmer and Haisken-DeNew 2012), many have concluded that it is U-shaped (recent examples using data from a variety of different sources can be found in Cheng et al. 2017; Blanchflower 2020a and 2020b). This literature is now voluminous, and useful summaries appear in three chapters on the subject

\footnotetext{
${ }^{1}$ Paris School of Economics - CNRS, Paris, France

${ }^{2}$ Sciences Po - OSC, Paris, France and Institut Universitaire de France, Paris, France

${ }^{*}$ Correspondence to: Hippolyte d'Albis, hdalbis@psemail.eu
} 
in the recent book edited by Mariano Rojas (Blanchflower and Oswald 2019; Clark 2019; Helliwell et al. 2019).

While there is probably majority agreement in the literature that the relationship is U-shaped, there is much more debate among scholars about why this is the case, and whether this pattern holds equally for all countries and all groups in society. Here, we contribute to the second of these discussions, and ask whether the U-shaped relationship between life satisfaction and age is flatter for individuals who are partnered. Partnership is obviously a relevant candidate as a variable in explanations of well-being, as being in a partnership requires substantial investments of time and resources and high levels of emotional involvement for the partners (Gove et al. 1990). Moreover, like other characteristics of family life that are important for well-being, being in a partnership is associated with greater financial security and less loneliness. Earlier work has found significant differences in well-being according to partnership status, although the size of these differences has been shown to vary across countries (Verbakel 2012). Moreover, an analysis of World Values Survey/European Values Survey data (Mikucka 2016) has indicated that the size of these differences has declined among men since the 1980s.

We are not the first to examine the question of whether being in a partnership flattens the U-shaped relationship between subjective well-being and age. Helliwell et al. (2019) introduced an interaction between marriage/cohabitation and age in subjective well-being regressions drawn from both the US Gallup Healthways data and the UK Annual Population Survey. They found a substantially flatter U-shaped relationship between well-being and age for partnered individuals based on their analysis of both of these cross-sectional datasets, which was only partly explained by control variables (sex, education, labour force status, log income and the number of children). A flatter U-shape for married people was also found in an analysis of the Gallup World Poll data by Jebb et al. (2020). The authors imposed a quadratic relationship between age and the Cantril ladder well-being question, though they argued that the difference between the two curves was not large.

In the current analysis, we use a very large-scale harmonised dataset covering 32 European countries, the EU-SILC, to first show that the U-shape holds in general in Europe. This is a very standard observation in the empirical literature. Moreover, as in Helliwell et al. (2019), we demonstrate that this U-shape is far flatter for partnered individuals, and that the age U-shape is mostly concentrated among those individuals who are not partnered. This pattern is not found for all of the subjective evaluations in the EU-SILC data. The protective role of being in a partnership is found to be particularly important for people's overall life satisfaction, their satisfaction with their financial situation and their satisfaction with their personal relationships, but not at all for their job satisfaction or their satisfaction with time use. Thus, being partnered seems to protect people against the typical decline in well-being associated with middle age in at least certain domains of subjective well-being.

This first result is, however, less clear in the panel data. Fixed-effect analyses using the BHPS (UK), the SOEP (Germany) and the HILDA (Australia) reveal 
a U-shape in age for both partnered and non-partnered individuals, although the U-shape for the partnered individuals was again found to be somewhat flatter. We consider a number of explanations for this gap between the cross-sectional and the panel results. In particular, we do not believe that this discrepancy reflects the different countries in the cross-sectional and panel analyses, or differential mortality (or attrition in general) between the partnered and the non-partnered individuals. However, we do find some evidence of compositional effects that tend to flatten the $\mathrm{U}$-shape in age for the partnered individuals in the cross-sectional data. Specifically, we observe that those individuals who experience a break-up in their forties and fifties are noticeably less satisfied with their lives than those who experience a breakup at younger or older ages. This composition or shift-share effect will mechanically increase the average well-being among those individuals who remain partnered in their forties and fifties, and will tend to produce a less U-shaped age profile.

The remainder of the paper is organised as follows. In Section 2, we describe the European data that we use and the hypotheses that we test, followed by the main cross-sectional results. In Section 3, we present our analysis of panel data in selected countries. Section 4 concludes.

\section{Life satisfaction, age and partnership: cross-sectional analysis of EU-SILC data}

Our main analysis of subjective well-being by age and gender is based on data from the EU Statistics on Income and Living Conditions (EU-SILC) survey conducted by Eurostat, which provides harmonised information on hundreds of thousands of respondents in more than 30 European countries. This annual survey is the reference source for comparative statistics on income distribution and social inclusion in the European Union (EU). The EU-SILC provides (micro-level) information on both households and individuals on topics such as income and tax, material deprivation, housing conditions, employment, childcare, health and education.

Additional specific topics are covered in ad hoc annual modules, which complement the core variables that appear in every EU-SILC wave by providing supplementary information that highlights different aspects of social inclusion. Examples of the topics covered in these modules are the intergenerational transmission of poverty (2005 and 2011), social participation (2006 and 2015), indebtedness (2008) and the intra-household sharing of resources (2010). The EU-SILC 2013 ad hoc module provided information on well-being for 350,000 individuals in 32 different European countries. ${ }^{1}$

\footnotetext{
1 Austria, Belgium, Bulgaria, Switzerland, Cyprus, the Czech Republic, Germany, Denmark, Estonia, Greece, Spain, Finland, France, Croatia, Hungary, Ireland, Iceland, Italy, Lithuania, Luxembourg, Latvia, Malta, the Netherlands, Norway, Poland, Portugal, Romania, Serbia, Sweden, Slovenia, Slovakia and the United Kingdom.
} 
EU-SILC is a panel dataset with a four-year rotation (so that $25 \%$ of the sample are replaced each year). The 2018 EU-SILC wave repeated parts of the 2013 wellbeing module, although the gap between the two waves was large enough that none of the 2013 respondents remained in the 2018 sample. However, in this analysis, we carry out a cross-sectional analysis of the 2013 data only, as the 2018 module on well-being did not include all of the well-being variables that we will consider below.

Among the aims of the 2013 well-being module was to place greater emphasis on individuals' feelings of well-being, which are known to be highly correlated with levels of social inclusion and labour market integration. The module covered subjects like satisfaction with different life domains, the emotional state of mind, social deprivation, and the option to ask for help if necessary. All questions were posed at the individual level (to household members aged 16 and older).

Survey design can have an impact on individual replies. Thus, the placement of the well-being module in the survey questionnaire, the response scales used and how respondents perceive the questions in different countries can influence the responses. As the order of the questions within the module and the position of the module questionnaire in the survey were mostly standardised across countries, Eurostat considers the contribution of these parameters to the overall context-related bias to be minimal. For further details on assessments of the implementation of the 2013 EU-SILC module on well-being, see Eurostat (2012a).

The main dependent variable in our analysis is "overall life satisfaction", with replies on a scale from zero (not at all satisfied) to 10 (completely satisfied). ${ }^{2}$ The life satisfaction variable is intended to capture the respondent's broad, reflective appraisal of his/her life as a whole. The term "life" is intended to be understood here as all of the areas of a person's life at a particular point in time (Diener 2006). The variable captures the respondent's opinion/feeling about how s/he is feeling "these days", rather than specifying an explicit longer or shorter time period. Thus, the intent is not to measure the individual's current emotional state (or affect), but for him/her to make a reflective judgement about his/her satisfaction with his/her life overall (Eurostat 2012b). ${ }^{3}$

The weighted average overall life satisfaction score in the 2013 EU-SILC, covering all 32 European countries and considering respondents up to age 80, is seven. Table A.1 in the Appendix presents the descriptive statistics of the life satisfaction scores and the percentage of the respondents who are partnered by the different age groups we will analyse.

The average overall life satisfaction score appears in the middle of the ranking of the more specific domain satisfaction variables: satisfaction is lower for "trust in the political system", "trust in the legal system", "trust in others", "satisfaction

\footnotetext{
2 The validity of life satisfaction as a measure of well-being is discussed in Clark (2016).

3 However, (recent) mood and life satisfaction may be strongly correlated with each other, and be similarly correlated with a number of explanatory variables: see Clark (2016).
} 
Figure 1:

Overall life satisfaction in 32 European countries

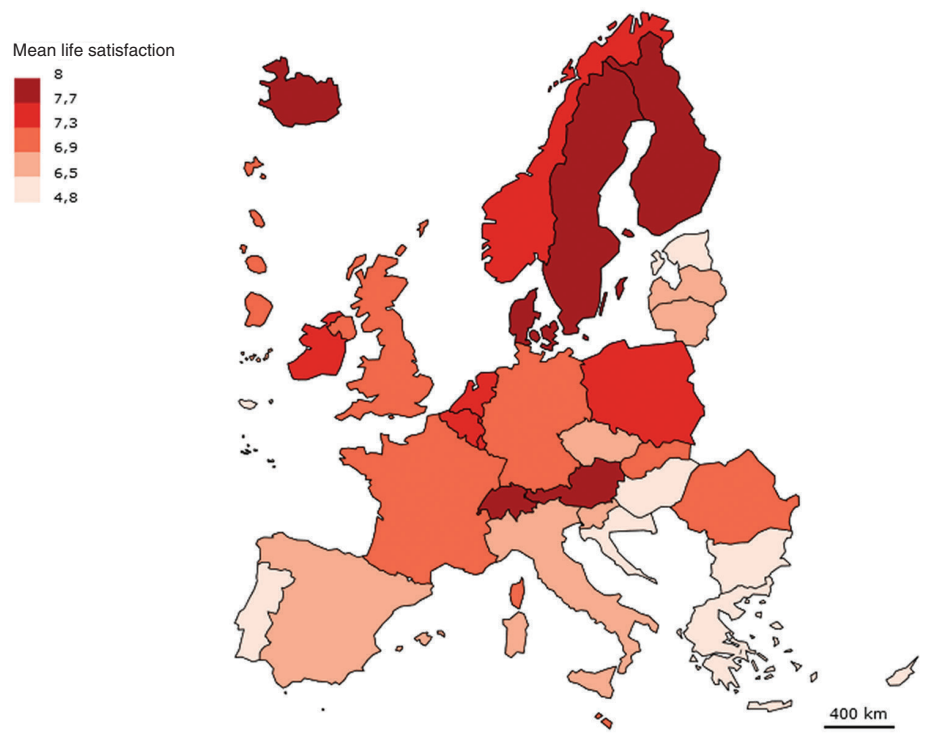

Source: EU-SILC 2013.

with the financial situation", "trust in the police" and "satisfaction with time use"; satisfaction is higher for "satisfaction with recreational or green areas", "satisfaction with the living environment", "job satisfaction", "satisfaction with commuting times", "meaning of life", "satisfaction with accommodation" and "satisfaction with personal relationships". It should, however, be emphasised that the "overall life satisfaction" score comes from a question in its own right in the SILC questionnaire, and is not calculated as a summary measure of the various domain satisfaction scores.

The cross-country distribution of life satisfaction in our analysis is similar to that found in other surveys (see, for example, the distribution of the answers to the Cantril ladder question in the Gallup World Poll, which is presented in the annual World Happiness Report). Overall life satisfaction is generally shown to be higher in Northern Europe and lower in Southern Europe, as illustrated in Figure 1's heatmap.

The lowest life satisfaction score on the $0-10$ scale is found in Bulgaria (4.8), followed by in Serbia (4.9) and Portugal (6.1); and the highest score is found in Switzerland (8.0), followed by in Finland and Denmark (both 7.9).

The relationship of life satisfaction to age and sex is depicted in Figure 2. As throughout the empirical analysis, here we only consider respondents up to age 80 . Across all 32 countries in the study sample, women are found to be less satisfied at higher ages and more satisfied at younger ages than men. 
Figure 2:

Overall life satisfaction by age and sex

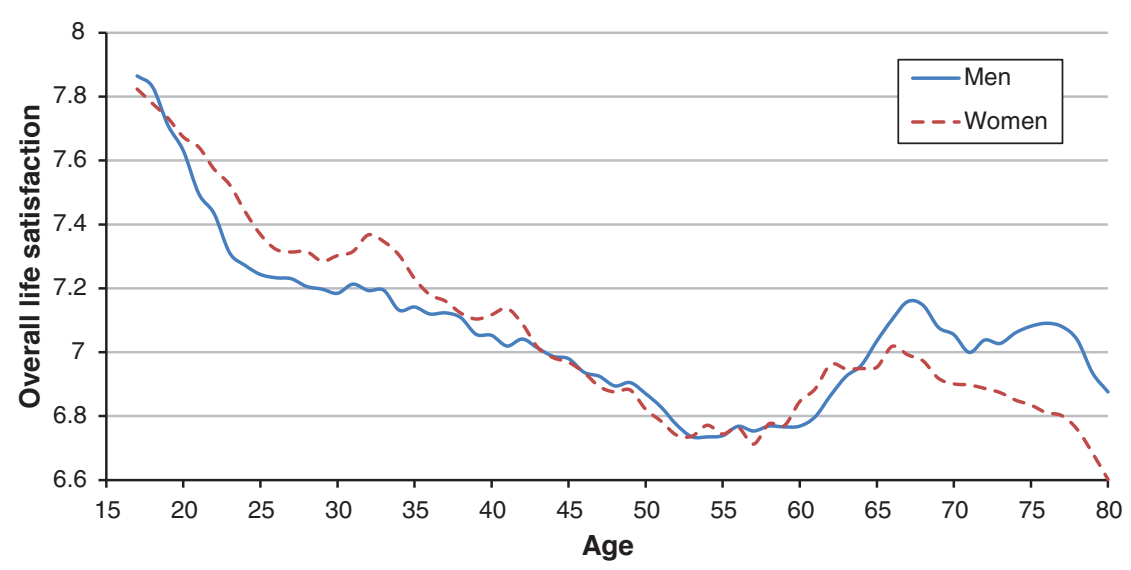

Note: The figures here are weighted averages over 32 European countries. The points refer to three-year (with respect to age) moving averages.

Source: EU-SILC 2013.

However, we find no systematic gender gap in overall life satisfaction within couples, independent of the man's age, the woman's age and the size and direction of the age difference within the couple. The distribution of the absolute difference in life satisfaction between the two partners is normally distributed around zero, with $40 \%$ of couples reporting zero difference. ${ }^{4}$ It may be the case that the gender gap in life satisfaction at younger and older ages shown in Figure 2 reflects the respondents' partnership status. Indeed, we find that women are more likely to be partnered at younger ages and less likely to be partnered at older ages, as illustrated in Figure 3.

To find out whether the gender difference in life satisfaction disappears once we control for partnership status, we estimate now, in a first step, life satisfaction as a function of age, sex and partner status. We control for country fixed effects in order to focus on within-country variations only. The results presented in the following are based on OLS regressions.

The regression results appear in Table 1, with first a stripped-down model controlling only for age (as 10-year age group dummies) and country dummies; then a second specification with an additional control for sex; and, finally, a third specification controlling for both sex and partner status. An individual is considered as "partnered" when s/he is observed to be cohabiting with a partner at the time of

\footnotetext{
4 Guven et al. (2012) showed using SOEP data for Germany that life satisfaction gaps between partners predict future separation, but only when the woman is less satisfied than the man.
} 


\section{Figure 3:}

\section{Partnership status by age and sex}

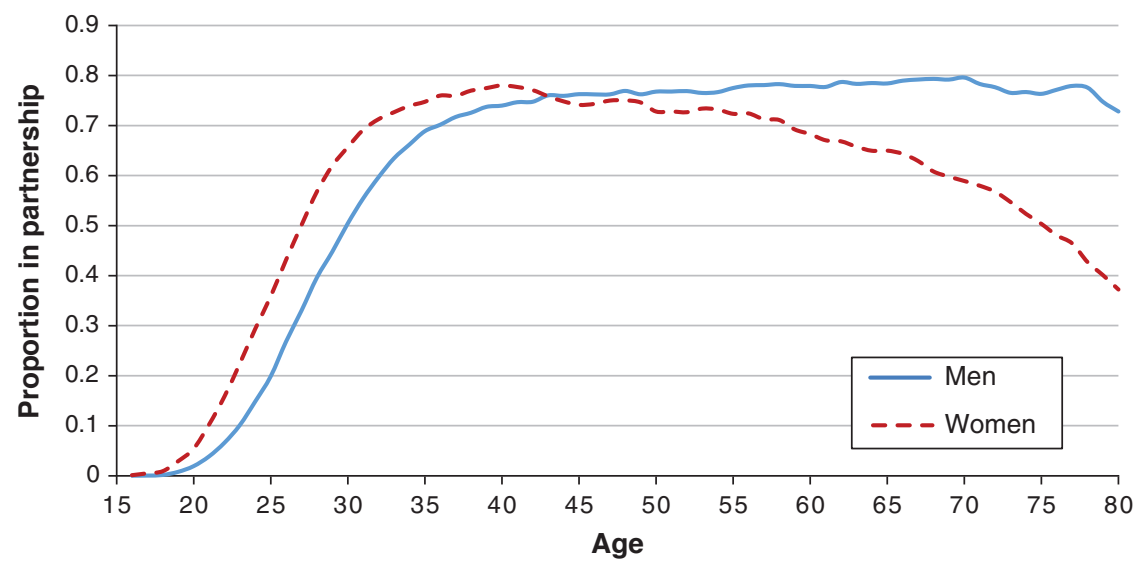

Note: The figures here are weighted averages over 32 European countries. The points refer to three-year (with respect to age) moving averages.

Source: EU-SILC 2013.

the survey. Note, however, that the results are robust to considering only those who are married as being "partnered". As the omitted age category in these regressions is $40-49$, the estimated coefficients on the dummy variables for the other 10-year age categories should be read as relative to this age group.

Column 1 indicates that life satisfaction is highest for teenagers and lowest for those in their fifties, and again for those in their seventies. ${ }^{5}$ Column 2 then controls for sex, which barely changes the estimated age coefficients. The difference in life satisfaction between men and women appears to be insignificant once we control for age. Finally, column 3 shows that there is a small but significant gender difference, with women being somewhat more satisfied than men once we control for age and partnership. ${ }^{6}$ Partnership itself turns out to be highly correlated with overall life

5 The finding that the U-shape bottoms out around the fifties has often been reported in the literature. Based on BHPS data, Clark (2019) found that life satisfaction reaches its lowest point at age 42 in cross-sectional analysis, and between ages 40-50 in panel regressions. In an analysis of four waves of the World Values Survey, Blanchflower and Oswald (2008) found that the average minimum level is reached at age 43. Graham and Ruiz Pozuelo (2017) reported that the minimum level is reached between the ages of 40 and 60 in 44 out of the 46 countries they analysed using Gallup World Poll data. A very thorough recent analysis of the U-shape using many different datasets appeared in Blanchflower (2020a), who again found that the U-shape bottoms out most often in the forties or fifties.

6 The finding that women report higher life satisfaction than men is common in the literature: see Nolen-Hoeksema and Rusting (1999). 
Table 1:

Life satisfaction by age, controlling for sex and partnership status

\begin{tabular}{|c|c|c|c|}
\hline & \multicolumn{3}{|c|}{ Overall life satisfaction } \\
\hline \multicolumn{4}{|l|}{ Age category: } \\
\hline \multirow[t]{2}{*}{ Ages 15-19 } & $0.924^{* * *}$ & $0.924^{* * *}$ & $1.430^{* * *}$ \\
\hline & $(44.86)$ & $(44.84)$ & $(67.81)$ \\
\hline \multirow[t]{2}{*}{ Ages 20-29 } & $0.419^{* * *}$ & $0.419^{* * *}$ & $0.742^{* * *}$ \\
\hline & $(33.03)$ & $(33.01)$ & $(56.99)$ \\
\hline \multirow[t]{2}{*}{ Ages 30-39 } & $0.253^{* * *}$ & $0.253^{* * *}$ & $0.286^{* * *}$ \\
\hline & $(21.61)$ & $(21.61)$ & $(24.71)$ \\
\hline Ages 40-49 & Ref. & Ref. & Ref. \\
\hline \multirow[t]{2}{*}{ Ages 50-59 } & $-0.225^{* * *}$ & $-0.225^{* * *}$ & $-0.217^{* * *}$ \\
\hline & $(-20.81)$ & $(-20.81)$ & $(-20.36)$ \\
\hline \multirow[t]{2}{*}{ Ages 60-69 } & $-0.0644^{* * *}$ & $-0.0645^{* * *}$ & $-0.0373^{* * *}$ \\
\hline & $(-5.88)$ & $(-5.88)$ & $(-3.44)$ \\
\hline \multirow[t]{2}{*}{ Ages 70-80 } & $-0.229^{* * *}$ & $-0.229^{* * *}$ & $-0.0836^{* * *}$ \\
\hline & $(-21.10)$ & $(-21.09)$ & $(-7.71)$ \\
\hline \multicolumn{4}{|l|}{ Sex: } \\
\hline Male & / & Ref. & Ref. \\
\hline \multirow[t]{2}{*}{ Female } & / & -0.00494 & $0.0493^{* * *}$ \\
\hline & & $(-0.75)$ & (7.57) \\
\hline \multicolumn{4}{|l|}{ Partnership status: } \\
\hline Non-partnered & / & / & Ref. \\
\hline \multirow[t]{2}{*}{ Partnered } & / & / & $0.670^{* * *}$ \\
\hline & & & $(92.52)$ \\
\hline \multirow[t]{2}{*}{ Constant } & $7.838^{* * *}$ & $7.840^{* * *}$ & $7.301^{* * *}$ \\
\hline & $(371.15)$ & $(366.08)$ & $(332.44)$ \\
\hline Country FE & Yes & Yes & Yes \\
\hline$N$ & 370074 & 370074 & 370074 \\
\hline Adj. $R$-sq & 0.153 & 0.153 & 0.172 \\
\hline
\end{tabular}

Note: These are OLS regressions with country-fixed effects. Ages 15-80. T-statistics appear in parentheses. ${ }^{*} p<0.05,{ }^{* *} p<0.01,{ }^{* * *} p<0.001$.

Source: EU-SILC 2013.

satisfaction, with partnered individuals being significantly more satisfied than nonpartnered individuals. The effect size here is large, at two-thirds of a life satisfaction point, or almost one-third of a standard deviation (see the figures in the last column of the first panel of Appendix Table A.1). A comparison of columns 1 and 3 of Table 1 shows that controlling for partnership deepens the U-shape, which again suggests that partnership plays a role in the age-satisfaction relationship.

To see whether the age pattern of life satisfaction differs significantly between the partnered and the non-partnered respondents, we now run separate regressions 
Table 2:

\section{Life satisfaction by partner status}

\begin{tabular}{|c|c|c|c|c|c|}
\hline & \multicolumn{5}{|c|}{ Overall life satisfaction } \\
\hline & Partnered & Partnered & Non-partn. & Non-partn. & All \\
\hline \multicolumn{6}{|l|}{ Age category: } \\
\hline Ages 15-19 & $\begin{array}{r}0.257 \\
(1.40)\end{array}$ & $\begin{array}{r}0.245 \\
(1.33)\end{array}$ & $\begin{array}{l}1.624^{* * *} \\
(62.62)\end{array}$ & $\begin{array}{l}1.628^{* * *} \\
(62.73)\end{array}$ & $\begin{array}{l}1.690^{* * *} \\
(47.42)\end{array}$ \\
\hline Ages $20-29$ & $\begin{array}{l}0.271^{* * *} \\
(13.59)\end{array}$ & $\begin{array}{l}0.265^{* * *} \\
(13.27)\end{array}$ & $\begin{array}{l}1.076^{* * *} \\
(52.20)\end{array}$ & $\begin{array}{l}1.082^{* * *} \\
(52.36)\end{array}$ & $\begin{array}{l}1.065^{* * *} \\
(37.18)\end{array}$ \\
\hline Ages $30-39$ & $\begin{array}{l}0.255^{* * *} \\
(19.56)\end{array}$ & $\begin{array}{l}0.253^{* * *} \\
(19.43)\end{array}$ & $\begin{array}{l}0.392^{* * *} \\
(16.64)\end{array}$ & $\begin{array}{l}0.396^{* * *} \\
(16.80)\end{array}$ & $\begin{array}{l}0.465^{* * *} \\
(14.23)\end{array}$ \\
\hline Ages $40-49$ & Ref. & Ref. & Ref. & Ref. & Ref. \\
\hline Ages $50-59$ & $\begin{array}{l}-0.235^{* * *} \\
(-19.79)\end{array}$ & $\begin{array}{l}-0.234^{* * *} \\
(-19.69)\end{array}$ & $\begin{array}{l}-0.148^{* * *} \\
(-6.55)\end{array}$ & $\begin{array}{l}-0.150^{* * *} \\
(-6.63)\end{array}$ & $\begin{array}{l}-0.184^{* * *} \\
(-5.47)\end{array}$ \\
\hline Ages $60-69$ & $\begin{array}{l}-0.104^{* * *} \\
(-8.58)\end{array}$ & $\begin{array}{l}-0.101^{* * *} \\
(-8.31)\end{array}$ & $\begin{array}{l}0.164^{* * *} \\
(7.32)\end{array}$ & $\begin{array}{l}0.158^{* * *} \\
(7.06)\end{array}$ & $\begin{array}{l}0.129^{* * *} \\
(3.69)\end{array}$ \\
\hline Ages $70-80$ & $\begin{array}{l}-0.203^{* * *} \\
(-15.61)\end{array}$ & $\begin{array}{l}-0.196^{* * *} \\
(-15.02)\end{array}$ & $\begin{array}{l}0.163^{* * *} \\
(8.12)\end{array}$ & $\begin{array}{l}0.154^{* * *} \\
(7.60)\end{array}$ & $\begin{array}{l}0.279^{* * *} \\
(8.41)\end{array}$ \\
\hline \multicolumn{6}{|c|}{ 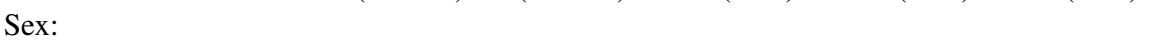 } \\
\hline Male & / & Ref. & / & Ref. & Ref. \\
\hline Female & / & $\begin{array}{l}0.0554^{* * *} \\
(7.01)\end{array}$ & l & $\begin{array}{l}0.0486^{* * *} \\
(4.15)\end{array}$ & $\begin{array}{l}0.0728^{*} \\
(2.32)\end{array}$ \\
\hline \multicolumn{6}{|l|}{ Partnership status: } \\
\hline Non-partnered & / & l & / & / & Ref. \\
\hline Partnered & / & l & / & / & $\begin{array}{l}0.953^{* * *} \\
(35.07)\end{array}$ \\
\hline \multicolumn{6}{|c|}{ Interaction: AgeCat\#PartnershipStatus\#Sex } \\
\hline $\begin{array}{l}\text { Ages } 15-19, \\
\text { non-partnered, female }\end{array}$ & & & & & $\begin{array}{l}-0.0981^{*} \\
(-1.99)\end{array}$ \\
\hline $\begin{array}{l}\text { Ages } 15-19, \\
\text { partnered, male }\end{array}$ & & & & & $\begin{array}{l}-1.052^{* *} \\
(-2.68)\end{array}$ \\
\hline $\begin{array}{l}\text { Ages } 15-19, \\
\text { partnered, female }\end{array}$ & & & & & $\begin{array}{l}-1.600^{* * *} \\
(-7.11)\end{array}$ \\
\hline $\begin{array}{l}\text { Ages } 20-29, \\
\text { non-partnered, female }\end{array}$ & & & & & $\begin{array}{l}0.0767 \\
(1.96)\end{array}$ \\
\hline $\begin{array}{l}\text { Ages } 20-29, \\
\quad \text { partnered, male }\end{array}$ & & & & & $\begin{array}{l}-0.851^{* * *} \\
(-18.98)\end{array}$ \\
\hline $\begin{array}{l}\text { Ages } 20-29, \\
\text { partnered, female }\end{array}$ & & & & & $\begin{array}{l}-0.801^{* * *} \\
(-13.27)\end{array}$ \\
\hline $\begin{array}{l}\text { Ages } 30-39, \\
\text { non-partnered, female }\end{array}$ & & & & & $\begin{array}{l}-0.113^{*} \\
(-2.51)\end{array}$ \\
\hline
\end{tabular}

Continued 
Table 2:

\section{Continued}

\begin{tabular}{|c|c|c|c|c|c|}
\hline & \multicolumn{5}{|c|}{ Overall life satisfaction } \\
\hline & Partnered & Partnered & Non-partn. & Non-partn. & All \\
\hline \multicolumn{6}{|c|}{ Interaction: AgeCat\#PartnershipStatus\#Sex } \\
\hline $\begin{array}{l}\text { Ages } 30-39, \\
\text { partnered, male }\end{array}$ & & & & & $\begin{array}{l}-0.240^{* * *} \\
(-6.22)\end{array}$ \\
\hline $\begin{array}{l}\text { Ages } 30-39, \\
\text { partnered, female }\end{array}$ & & & & & $\begin{array}{l}-0.232^{* * *} \\
(-3.90)\end{array}$ \\
\hline $\begin{array}{l}\text { Ages } 40-49, \\
\text { partnered, female }\end{array}$ & & & & & $\begin{array}{l}-0.0411 \\
(-1.14)\end{array}$ \\
\hline $\begin{array}{l}\text { Ages } 50-59, \\
\text { non-partnered, female }\end{array}$ & & & & & $\begin{array}{l}0.0562 \\
(1.29)\end{array}$ \\
\hline $\begin{array}{l}\text { Ages } 50-59, \\
\text { partnered, male }\end{array}$ & & & & & $\begin{array}{l}-0.0851^{*} \\
(-2.23)\end{array}$ \\
\hline $\begin{array}{l}\text { Ages } 50-59, \\
\text { partnered, female }\end{array}$ & & & & & $\begin{array}{l}-0.0667 \\
(-1.12)\end{array}$ \\
\hline $\begin{array}{l}\text { Ages } 60-69, \\
\text { non-partnered, female }\end{array}$ & & & & & $\begin{array}{l}0.0444 \\
(1.00)\end{array}$ \\
\hline $\begin{array}{l}\text { Ages } 60-69, \\
\text { partnered, male }\end{array}$ & & & & & $\begin{array}{l}-0.252^{* * *} \\
(-6.38)\end{array}$ \\
\hline $\begin{array}{l}\text { Ages } 60-69, \\
\text { partnered, female }\end{array}$ & & & & & $\begin{array}{l}-0.253^{* * *} \\
(-4.16)\end{array}$ \\
\hline $\begin{array}{l}\text { Ages } 70-80, \\
\text { non-partnered, female }\end{array}$ & & & & & $\begin{array}{l}-0.148^{* * *} \\
(-3.61)\end{array}$ \\
\hline $\begin{array}{l}\text { Ages } 70-80, \\
\text { partnered, male }\end{array}$ & & & & & $\begin{array}{l}-0.446^{* * *} \\
(-11.73)\end{array}$ \\
\hline $\begin{array}{l}\text { Ages } 70-80, \\
\text { partnered, female }\end{array}$ & & & & & $\begin{array}{l}-0.558^{* * *} \\
(-9.25)\end{array}$ \\
\hline Constant & $\begin{array}{l}8.046^{* * *} \\
(320.35)\end{array}$ & $\begin{array}{l}8.016^{* * *} \\
(314.81)\end{array}$ & $\begin{array}{l}7.179^{* * *} \\
(192.65)\end{array}$ & $\begin{array}{l}7.151^{* * *} \\
(188.88)\end{array}$ & $\begin{array}{l}7.097^{* * *} \\
(231.12)\end{array}$ \\
\hline Country FE & Yes & Yes & Yes & Yes & Yes \\
\hline$N$ & 232684 & 232684 & 137390 & 137390 & 370074 \\
\hline Adj. $R$-sq & 0.172 & 0.172 & 0.158 & 0.158 & 0.175 \\
\hline
\end{tabular}

Note: These are OLS regressions with country-fixed effects. Ages 15-80. $T$-statistics appear in parentheses. ${ }^{*} p<0.05,{ }^{* *} p<0.01,{ }^{* * *} p<0.001$.

Source: EU-SILC 2013.

for the two groups, and we interact age, sex and partnership status. Table 2 shows the results, with the first two columns referring to the partnered individuals and columns 3 and 4 referring to the non-partnered individuals. Columns 1 and 3 control for age and country-fixed effects only, while columns 2 and 4 also include sex. Finally, column 5 shows the estimation results when we analyse the whole sample together and introduce a full set of interactions between age, sex and partnership. 
The results are very different by partnership status. Columns 1 and 2 indicate that for the partnered individuals, the life satisfaction differences between most of the age groups are relatively small, with the U-shape of life satisfaction over age being rather flat. By contrast, for the non-partnered individuals, the effect size of the age coefficients is much larger, indicating a profound U-shaped relationship with life satisfaction, with those individuals in their fifties being the least satisfied. A comparison of columns 2 and 4 shows that the decline in life satisfaction from the teens to the fifties is almost four times larger for the non-partnered individuals than for the partnered individuals. ${ }^{7}$ Finally, women are again found to report slightly higher life satisfaction than men in both partnership groups.

Column 5 of Table 2 shows the estimated coefficients based on a specification with interaction terms between the following three categorical variables: "age category", "partnership status" and "sex". The interaction coefficients are difficult to interpret on their own. They can, however, be used to calculate the estimated levels of "overall life satisfaction' for each possible combination of age category, sex and partnership status. For example, the estimated level of life satisfaction for a non-partnered man aged 40 to 49 (the reference categories) is 7.097, which corresponds to the intercept in column 5. The estimated level of life satisfaction for a non-partnered woman aged 40 to 49 is 7.1698 , which is obtained by adding the estimated coefficient of "female' $(0.0728)$ to the intercept. The estimated life satisfaction level of a partnered women aged 15 to 19 is 8.2128 , which is calculated as follows: 7.097 (constant) +0.0728 (estimated coefficient on "female") +1.69 (estimated coefficient on age category "15-19") + 0.953 (estimated coefficient on "partnered") - 1.6 (estimated coefficient on the interaction "age 15-19, partnered, female"). ${ }^{8}$

Figure 4 illustrates these estimated life satisfaction scores for each possible combination of age category, sex and partner status using the numbers from column 5 of Table 2. While life satisfaction is clearly U-shaped for the nonpartnered individuals, the pattern is relatively flat for the partnered individuals. The U-shape is the most profound for the non-partnered men, who are the least satisfied at ages 50 to 59, and are somewhat more satisfied than the non-partnered women at ages 70-80. Note that the confidence intervals are large for the partnered women and men at ages 15 to 19 , as few of the respondents cohabit with a partner before the age of 20 .

Figure 4 further shows that within each age and partnership category, the gender difference in life satisfaction is small. Independent of sex, the main difference in life satisfaction found among the groups studied is between the partnered and the non-partnered individuals, especially in mid-life. Thus, based on the raw data, the

\footnotetext{
7 Partnership is then not only associated with higher mean life satisfaction, but also with lower variance, which might be thought to be valuable in its own right (see Clark et al. 2016).

8 Note that all of our estimations include country fixed effects, so that the estimated coefficients refer to within-country differences in life satisfaction.
} 
Figure 4:

Illustration of the predictive margins

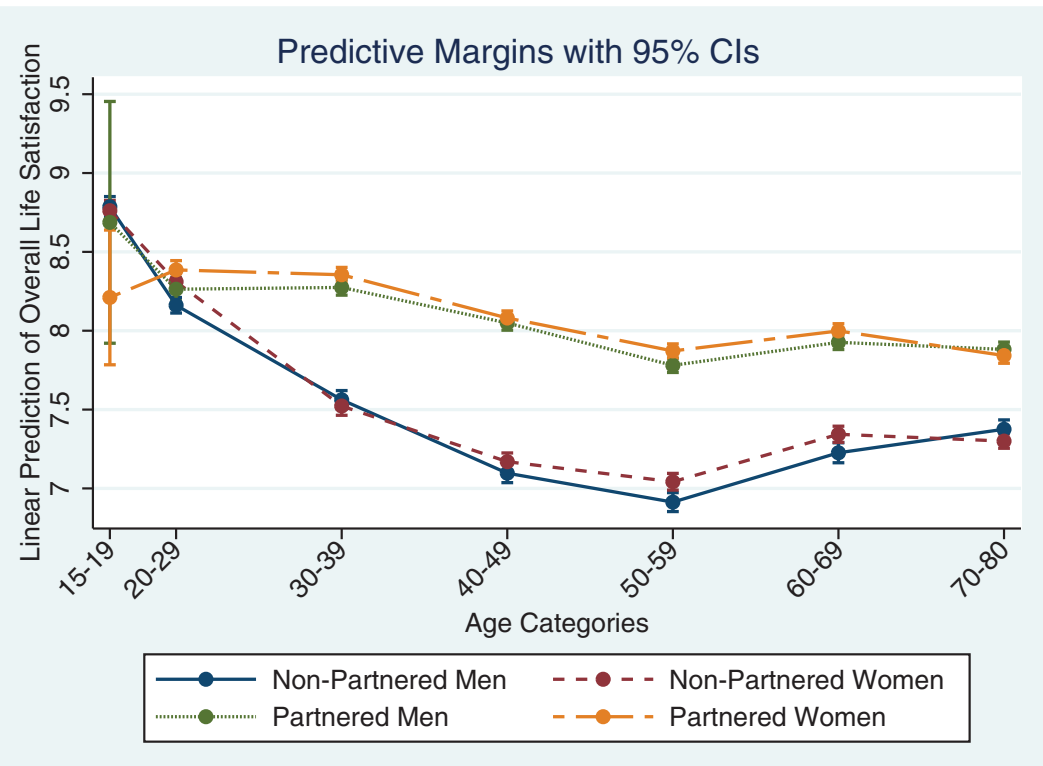

Note: These are calculated from the OLS regression with country-fixed effects in column 5 of Table 2; ages $15-80$. Source: EU-SILC 2013.

gender difference in life satisfaction at younger and at older ages, as illustrated in Figure 2, is due to differences in partnership status. Until their early forties, women are happier than men because they are more likely than men to be partnered at these ages. From their sixties onwards, men are happier than women because they are more likely than women to be partnered at these older ages.

The results above come from a very stripped-down specification. However, they do not change in nature when we add more variables to look for potential confounders in the relationship between age, partnership and life satisfaction. We consider country of birth (Native, European, and other), the degree of urbanisation, living in a relatively rich country (as measured by GDP per capita in PPP terms), education, and both individual and household income. Within each education and income group, the U-shaped pattern of life satisfaction remains much sharper for the non-partnered than the partnered individuals.

We also consider different measures of subjective well-being, replacing "life satisfaction" with "meaning of life", "satisfaction with financial situation", "satisfaction with personal relationships" and the "ability to make ends meet". We find a flatter U-shape for the partnered than for the non-partnered individuals for all four of these variables. In this case, the protection derived from being in a partnership may be 
partly financial. By contrast, we find no significant differences by age group, sex or partnership status for job satisfaction. ${ }^{9}$ Finally, for satisfaction with time use, we find a U-shape in age, but with a minimum level (at age 30 to 39) that is lower than the figure for overall life satisfaction shown in Table 2. The highest level of satisfaction with time use is observed at ages 60 to 69. Few significant differences in satisfaction with time use between men and women or between partnered and non-partnered individuals are found.

We might wonder whether our results for being in a partnership reflect the presence of children in the household. The EU-SILC only provides information on the number and the ages of children who are living in the respondent's household. Moreover, having children at home becomes increasingly selective as the respondents grow older, when empty-nesting becomes more prevalent. We therefore controlled for children by limiting the sample to individuals aged 16 to $44 .{ }^{10}$ We find that overall life satisfaction does not differ significantly by age for men and women with children, whereas it drops significantly from age 16 to age 44 for both childless men and childless women. However, within the group of partnered individuals, we detect no significant differences in life satisfaction by age between childless individuals and those with children. Thus, the presence of children seems to play a less important role in overall life satisfaction than partnership status, at least for adults up to age $44 .{ }^{11}$

Finally, we carry out a country-by-country analysis. In each of the 32 European countries in our sample, the pattern of overall life satisfaction over age is found to be relatively flat for the partnered individuals and U-shaped for the non-partnered individuals, independent of their sex. ${ }^{12}$

Thus, our cross-sectional analysis based on the EU-SILC data suggests that the U-shaped pattern of life satisfaction by age holds for the non-partnered individuals, but largely disappears for the partnered individuals. It therefore appears that gender differences in overall life satisfaction are mainly caused by age-specific gender differences in the likelihood of being partnered. These results confirm the role of partnership in well-being, as, for example, reported by Verbakel (2012), whose analysis of the European Values Study showed that married people have the highest level of well-being, followed by those who are cohabiting, dating or single; and, finally, by those who are widowed or divorced. Our results presented above suggest

\footnotetext{
9 Helliwell et al. (2019) have suggested that the flatter U-shape for the married individuals may come about because "together spouses can better shoulder the extra demands that may exist in mid-life when career and other demands coincide". Our failure to confirm that this is the case for job or time-use satisfaction seems at odds with this hypothesis.

10 The Eurobarometer data used by Blanchflower and Clark (2020) also only include information on children living at home. They too cut the sample of parents at age 45 .

11 Only when we focus on satisfaction with time use do we find that partnered childless men and women report significantly higher satisfaction than partnered men and women with children.

12 We also note that overall life satisfaction is lower at higher ages in Eastern and Southern Europe than in Western and Northern Europe, conditional on partnership status and sex.
} 
that being partnered also matters for the dynamics of well-being across age groups. To help us understand why this is the case, we can turn to the abundant empirical literature showing that being in a partnership provides a person not only with additional resources, but also with social and emotional support, and with health benefits. First, it has been shown that the economic benefits of being partnered, and, in particular, of being married, increase with income if income is taxed in a progressive way. The observation that income tends to be hump-shaped with age may explain why the protective effect on well-being of being in a partnership is particularly strong for middle-aged people. Second, as noted above, numerous studies have suggested that being married is associated with better psychological health. However, there is no strong evidence that this effect varies with age. In an analysis of data from the Danish Twin Registry, Kohler et al. (2005) found a slight increase in this effect with age for men, but no significant change in this effect for women. Finally, marriage has been shown to be associated with better health and longevity (see Wilson and Oswald 2005, for an extensive survey). For instance, Ben-Shlomo et al. (1993) found that married men have a lower risk of dying from cardiovascular disease and lung cancer, and Helmer et al. (1999) reported that nevermarried people have a significantly higher risk of developing Alzheimer's disease. As these pathologies tend to occur in the second part of life, these findings may help to explain why the protective role of partnership is attenuated for younger people.

However, the results of a cross-sectional analysis will not necessarily correspond to the findings of an analysis of panel data if there is selection into partnership. It is not only possible that those individuals who are more satisfied select into partnerships (as in Stutzer and Frey 2006); it also is quite likely that people who are not satisfied with their relationships (and therefore have lower overall life satisfaction scores) select out of partnerships. ${ }^{13}$ Once these individuals find a new relationship that makes them happy, they will re-enter our sample of cohabiting partners. Both of these sources of endogeneity make it more difficult to conclude that being in a partnership protects against the U-shaped pattern, as the people who are partnered (or are non-partnered) are not the same people at different ages.

To shed light on the causal impact of being in a partnership on life satisfaction from a life-cycle perspective, we need to add panel data to our cross-sectional analysis. If being in a partnership indeed protects against the U-shaped pattern, we should find that the age profile of the partnered individuals in the panel data (i.e., within the same person) is flatter than that of the non-partnered individuals. The EU-SILC data does not help us here, given its four-year revolving design (and with information on life satisfaction only being available in the 2013 and 2018 survey waves). Thus, to examine this question, we turn to panel data from three of

13 See the lags and leads analysis of life satisfaction around the time of marital separation using Australian, British and German panel data in Figure 5.3 of Clark et al. (2018). 
the longest-running panel datasets: the HILDA (Australia), the BHPS (the United Kingdom) and the SOEP (Germany). ${ }^{14}$

\section{Life satisfaction, age and partnership in panel data}

Our analysis of panel data uses the same kinds of specifications as the crosssectional analysis above. The dependent variable, life satisfaction, is on a $0-10$ scale in the HILDA and the SOEP, and a 1-7 scale in the BHPS. ${ }^{15}$ We standardise the life satisfaction scores, so that our correlations are in terms of standard deviations. We consider those individuals aged 16-80, and split up age into dummies for the categories $15-19,20-29,30-39,40-49,50-59,60-69$ and 70-80. Partnered is a dummy for marriage or cohabitation. There is a heated discussion in the literature regarding the controls that should be introduced when analysing the relationship between subjective well-being and age. ${ }^{16}$ Here, as in our analysis of the EU-SILC data above, we take a minimalist approach, and introduce no other controls. All of our regressions include an individual fixed effect (which subsumes the effect of sex, plus any other variable that is time-invariant).

The regression to be estimated is

$$
\mathrm{LS}_{i t, m}=\boldsymbol{\beta}^{\prime} \mathbf{A g e}_{i t, m}+\mu_{i}+\varepsilon_{i t}
$$

where $\mathrm{LS}_{i t, m}$ is the life satisfaction of individual $i$ at time $t$ in marital status $m, \mathbf{A g e}_{i t, m}$ is a set of age dummies, and $\mu_{i}$ is the individual fixed effect. The presence of the latter implies that the age coefficients, $\boldsymbol{\beta}$, are identified by the same individual as $\mathrm{s} / \mathrm{h}$ moves from one age category to the next in the panel data.

The estimated coefficients from these regressions on our three panel datasets are depicted in Figure 5. The three columns refer to the BHPS, the SOEP and the HILDA, respectively. Within each column, the first graph shows the estimated age coefficients from a regression that includes the whole sample, while the second and the third graphs depict those for the partnered and the non-partnered individuals separately. The $Y$-axes are on the same scale within each row. It is immediately obvious that the largest age coefficients are found in the SOEP.

14 We have data from 2001-2016 for the HILDA, from 1984-2016 for the SOEP, and from 1996-2000 and 2000-2008 for the BHPS (these are the only BHPS waves that include life satisfaction information; the survey stopped in 2008).

15 Appendix Table A.1 lists the descriptive statistics for life satisfaction and the percentage partnered, by age, in these three panel surveys.

16 The discussion here revolves around confounders and mediators, with the former affecting both the dependent variable and the right-hand side variables, and the mediators describing the pathways via which the relationship from the right-hand side variable to the dependent variable pass. This distinction is less obvious when the explanatory variable is exogenous (such as age, sex or ethnicity). Adding controls helps to explain how the relationship works, but not whether there is a relationship in the first place. This debate is ongoing: see Blanchflower (2020a). 

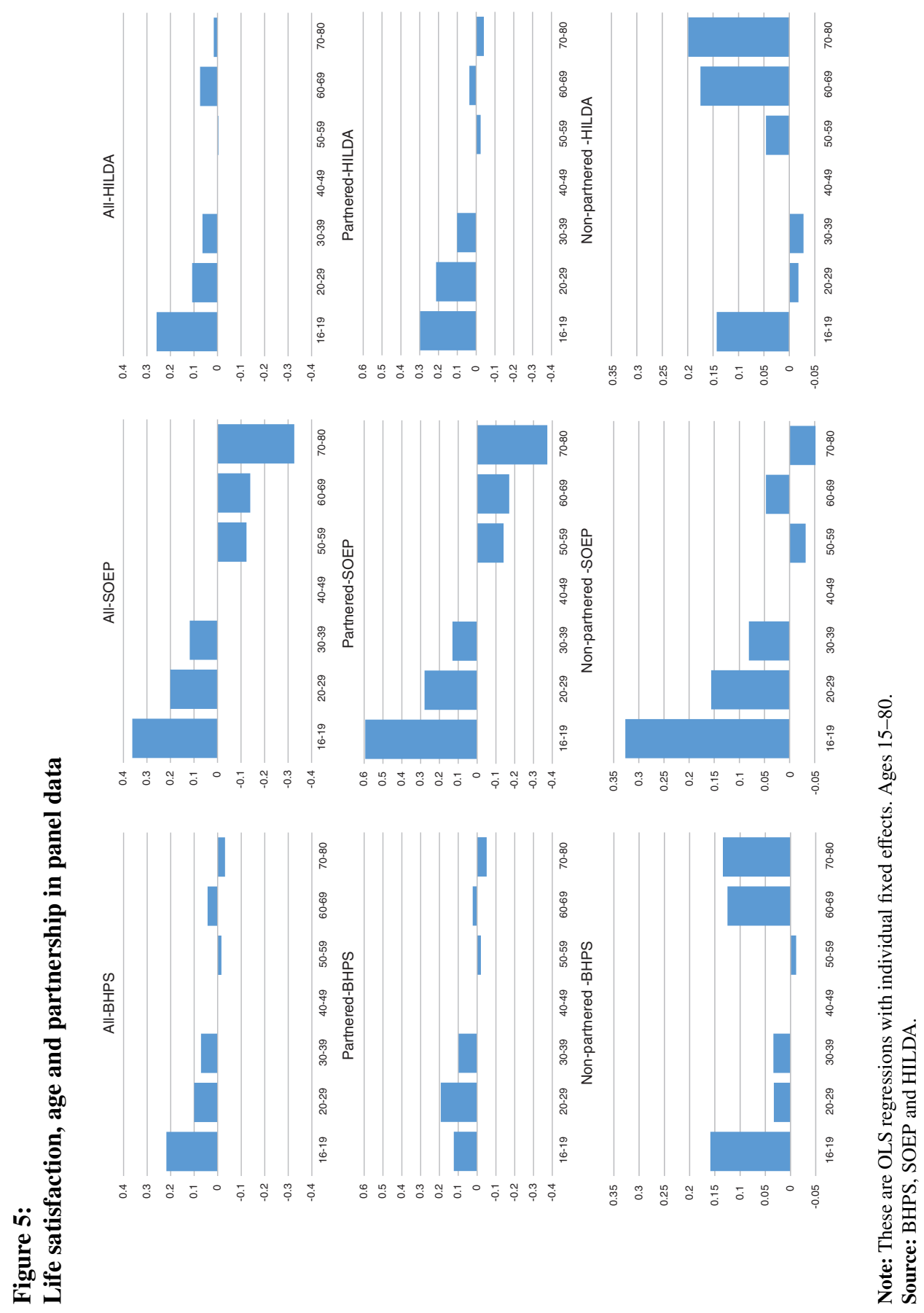
Looking at the first row, we can see that the estimated age coefficients suggest that there is something of a U-shaped relationship in both the BHPS and the HILDA. By contrast, the panel results for the SOEP produce a monotonically negative relationship between life satisfaction and age. ${ }^{17}$

The most important element of Figure 5 in the context of our analysis here is the comparison of the shapes of the estimated coefficients in the partnered and nonpartnered graphs in the second and third rows. A broad characterisation of the results is that the age profile is more U-shaped for the non-partnered than for the partnered individuals, as in the EU-SILC data. However, this distinction is somewhat less apparent in the SOEP, and, in general, there is still a noticeable age profile in life satisfaction for the partnered individuals (whereas the age profile in life satisfaction for the partnered individuals in the cross-sectional EU-SILC data was largely flat). ${ }^{18}$

Thus, there is only partial agreement between our pooled EU-SILC results presented in Section 2 and the results from the three panel datasets in Figure 5: i.e., in the panel data, the partnered individuals continue to drop down the first arm of the U-shape at least as much as the non-partnered individuals. Below, we consider a number of potential explanations for the differences between the pooled and panel results.

\subsection{Different countries}

There are 32 different countries in the EU-SILC, and only two of these countries appear in our panel analysis above. However, when we consider the EU-SILC results for the UK and Germany on their own, we see that they are the same as those for all of the 32 countries covered in Section 2 above.

17 We can speculate as to why the German results are so different. Note that this cannot be a cohort effect, as the estimated coefficients come from within-individual regressions. Even so, it may be the case that people who grew up during World War II are less equipped to deal with ageing, and that their age-life satisfaction profile is therefore different. We use SOEP waves from 1984 to 2016. Thus, the average person in the 50-59 age group in this dataset was born in 1945. The birth years for those aged 60-69 and 70-80 were 1935 and 1925 .

18 The year coverage of the three panels is not the same. All of our panel regressions include year dummies that will pick up any common macro effects that may be correlated with life satisfaction and marital status. It is, however, possible that the relationship between partnership and life satisfaction itself has changed over time (and within each individual, as these are all panel regressions). To check whether this is the case, we re-estimate the equations behind Figure 5 only from 2000 onwards, and then only for the overlap years for the three panels, from 2001 (the start of the HILDA) to 2008 (the end of the BHPS). Reassuringly, we find that the data shapes are similar to those in Figure 5. 


\subsection{Data comparability}

Alternatively, there could be some design issues in the BHPS, the SOEP and the HILDA that make the results of an analysis of life satisfaction and age based on the data from these surveys not comparable to the results of an analysis of 2013 crosssectional data from the EU-SILC. However, these three panel datasets have been very widely analysed in the literature, and when we look at them in a cross-sectional manner, we find exactly the same kind of U-shaped patterns as those displayed in Figure 4 above: i.e., there is a U-shape in age for both the partnered and the nonpartnered individuals. ${ }^{19}$

\subsection{Mortality}

The U-shape between life satisfaction and age is (of course) estimated using data on the living. Thus, one potential explanation for the upward-sloping arm of the U-shape is that the dissatisfied die off, leaving an increasingly selected sample of the (satisfied) living. ${ }^{20}$ As such, if mortality and subjective well-being were unrelated, the well-being profile of the older individuals would be skewed downwards.

Can mortality explain the different well-being age profiles for the partnered and the non-partnered individuals in the cross-sectional analyses? For this to be the case, we would first need to observe excess mortality among the partnered individuals (relative to the non-partnered individuals), and then that this excess mortality was especially pronounced in middle age. Neither of these possibilities appear likely.

First, the UK death rates suggest that there are "not enough" deaths to explain the U-shape: i.e., the cumulative death rate is only 11 per 1000 from age 16 to age 55, and is 63 per 1000 from age 16 to age 75 . Even taking the extreme position of assigning a life satisfaction value of zero to these missing people reduces average life satisfaction by less than 0.1 of a point at age 55, and by around 0.5 of a point at age 75 ; these figures are to be compared to the actual observed life satisfaction gap of -1.2 points at both ages.

Second, there would have to be excess mortality among the partnered individuals. However, the existing evidence (see Kravdal et al. 2018) suggests that there is a negative relationship between marriage and mortality: protecting the married from mortality means that the non-partnered individuals are more selected, such that their life satisfaction scores are "too high"-which is the opposite of what we find in Figure 4.

A related point is attrition, whereby individuals drop out of the panel for whatever reason. The likelihood of dropping out is known to be related to subjective wellbeing, and it is indeed the case that in all three of our panels, lower life satisfaction

19 This cross-sectional U-shape minimises at age 40-49 in the BHPS and the HILDA, and at 50-59 in the SOEP.

20 A well-known contribution here is Danner et al. (2001). 
at time $t$ predicts dropping out of the panel at time $t+1$. However, we find no significant difference in this satisfaction-attrition relationship by partnership status, or by partnership status by age group (mid-life, which we set at ages 35-55, versus the rest). Thus, selective attrition does not seem to explain our panel results.

\subsection{Selection into marriage}

Finally, we consider the role of selection into and out of a partnership, and whether this composition effect can explain the cross-sectional gap in life satisfaction between the partnered and the non-partnered individuals shown in Figure 4.

First, we find that the percentage of people who are partnered changes sharply with age. In the EU-SILC data, the percentage of people who are partnered is only $10 \%$ in the early twenties, but is $80 \%$ by age 40 . This figure tails off at older ages. One way of squaring the (flat) cross-sectional and (more U-shaped) panel results is selection into and out of marriage: each individual follows his/her own U-shape as $\mathrm{s} /$ he ages, but there are composition effects of different well-being types in and out of a partnership at different ages.

Following our results above, this would mean either that those individuals who select into a partnership in their thirties and forties are more satisfied types (in terms of Equation (1), that their average value of $\mu_{i}$ is higher) than those who become partnered in their twenties or sixties, and/or that those individuals who select out of marriage in their thirties or forties are unhappier types. Alternatively, we could allow for heterogeneity in the relationship between life satisfaction and being in a partnership, with those individuals who become partnered in their thirties and forties experiencing a greater life satisfaction boost from it than those who marry earlier or later.

Figures A.1 and A.2 in the Appendix investigate both of the above possibilities. In Figure A.1, the left-hand side shows the level of life satisfaction of those individuals who move from non-partnership to partnership status (this is the life satisfaction score they report in the year before they make this move), while the right-hand side shows the rise in life satisfaction reported by individuals as they move from being non-partnered in wave $t-1$ to being partnered at wave $t$. The three rows show these numbers for the BHPS, the SOEP and the HILDA.

To explain the difference between the pooled and the panel results, we would need those individuals who move from non-partnership to partnership status in their thirties and forties to be more satisfied types than those who make this transition earlier or later (on the left-hand side of the figure), or to enjoy a greater satisfaction boost from doing so (on the right-hand side of the figure): thus, we should be looking for hump-shapes in age.

Figure A.1 shows the results for the NP-P movers. In the BHPS and the SOEP data, there is some evidence of a hump-shape in life satisfaction levels (although this occurs in the twenties and thirties, rather than in the thirties and forties). When we look at the change in life satisfaction shown on the right-hand side, two points 
stick out. The first is that there is a large decline in life satisfaction associated with teen partnership in the UK and Australia, but a large rise in Germany. The second is that the increase in life satisfaction is larger for those individuals who become partnered in their fifties, except in Australia. This will flatten the cross-sectional age profile.

Figure A.2 shows the results of the same exercise for those individuals who leave a partnership. There is no column for ages 16-19 here, as very few people separate before age 20. As noted above, we are looking for a U-shaped relationship. There is no evidence of such a relationship in the change in life satisfaction around the time of transition, as shown on the right-hand side. However, the levels of life satisfaction shown on the left-hand side do display a distinct U-shape: those individuals who move out of a partnership in their forties and fifties are notably less satisfied than those who leave at other ages. Thus, the flatter age profile for the partnered individuals in the cross-sectional data may be partly explained by a composition effect, with the unhappy individuals moving from partnered to nonpartnered status at this age, which mechanically raises the average life satisfaction score of those who remain in the partnered group.

\section{Conclusion}

While the finding in the literature that there is a U-shaped relationship between life satisfaction and age is robust, it has not been fully explored. This relationship has been found for multiple countries and datasets (Blanchflower 2020a and 2020b), and often continues to hold even when large numbers of controls are considered, ranging from observable mid-life burdens to aspirations. Thus, there is still much to be learned about the reasons why the U-shaped pattern exists. In this article, we have analysed the possible role of a rather intuitive factor-being in a partnership - and examined the question of whether being partnered could help protect individuals against the mid-life decline in satisfaction. In general, we expected to find that the U-shape would be deeper for those individuals who lacked certain physical or emotional resources.

Our findings were mixed, and depended strongly on the type of data analysed. The life satisfaction of the partnered individuals was shown to be rather flat with age in the cross-sectional data we analysed, but displayed a more U-shaped pattern in the three panel datasets we considered. We believe this difference partly reflects a composition effect: i.e., that those who leave partnerships in their forties and fifties are noticeably less satisfied with their lives than those who break up at younger or older ages.

To study how key demographic, economic and psychological variables change over the life-cycle, reliable longitudinal datasets are needed. As we have seen above, imputing life-cycle changes from cross-sectional data can be hazardous. While developing and supporting panel datasets will require considerable investments by public funding agencies, longitudinal data are essential to research on the 
evolution of societies, which are composed of individuals who change over time. Having access to panel datasets will also facilitate inter-disciplinary work, with wellbeing arguably being a good example of a topic that could be analysed jointly by researchers in a number of different fields.

\section{Acknowledgments}

We gratefully acknowledge financial support from the Agence Nationale de la Recherche within the JPI MYBL framework (Award No. ANR-16-MYBL-0001-02) and EUR grant ANR-17-EURE-0001. We thank Conchita D'Ambrosio, Andrew Oswald, Nick Powdthavee and seminar participants at ISQOLS (Granada), the Age Well Accounts workshop in Vienna and the Demographic Aspects of Human Wellbeing Conference for their helpful comments. Two referees made a number of very useful points that helped us make our analysis clearer. We are very grateful to Anthony Lepinteur for his help and advice with the panel data analysis.

\section{References}

Ben-Shlomo, Y., G. D. Smith and M. Shipley 1993. Magnitude and causes of mortality differences between married and unmarried men. Journal of Epidemiology and Community Health 47: 200-205.

Blanchflower, D. G. 2020a. Is happiness U-shaped everywhere? Age and subjective wellbeing in 145 countries. Journal of Population Economics 34: 575-624. https://doi.org/10. 1007/s00148-020-00797-z

Blanchflower, D. G. 2020b. Unhappiness and age. Journal of Economic Behavior and Organization 176: 461-488. https://doi.org/10.1016/j.jebo.2020.04.022

Blanchflower, D. G. and A. E. Clark 2020. Children, unhappiness and family finances. Journal of Population Economics 34: 625-653. https://doi.org/10.1007/s00148-020-00798-y

Blanchflower, D. G. and A. J. Oswald 2008. Is wellbeing U-shaped over the life cycle? Social Science $\mathcal{E}$ Medicine 66: 1733-1749. https://doi.org/10.1016/j.socscimed.2008.01.030

Blanchflower, D. G. and A. J. Oswald 2019. Do humans suffer a psychological low in midlife? Two approaches (with and without controls) in seven data sets. In The economics of happiness: How the Easterlin paradox transformed our understanding of well-being and progress, ed M. Rojas, 439-453. New York: Springer. https://doi.org/10.1007/978-3030-15835-4_19

Cheng, T., A. J. Oswald and N. Powdthavee 2017. Longitudinal evidence for a midlife nadir in human well-being: Results from four data sets. Economic Journal 127: 126-142. https://doi.org/10.1111/ecoj.12256

Clark, A. E. 2016. SWB as a measure of individual well-being. In Oxford handbook of well-being and public policy, eds M. Adler and M. Fleurbaey. Oxford: Oxford University Press. https://doi.org/10.1093/oxfordhb/9780199325818.013.17 
Clark, A. E. 2019. Born to be mild? Cohort effects don't (fully) explain why well-being is U-shaped in age. In The economics of happiness: How the Easterlin paradox transformed our understanding of well-being and progress, ed M. Rojas, 387-408. New York: Springer. https://doi.org/10.1007/978-3-030-15835-4_17

Clark, A. E., S. Flèche, R. Layard, N. Powdthavee and G. Ward 2018. The Origins of happiness: The science of well-being over the life-course. Princeton NJ: Princeton University Press.

Clark, A. E., S. Flèche and C. Senik 2016. Economic growth evens-out happiness: Evidence from six surveys. Review of Income and Wealth 62: 405-419. https://doi.org/10.1111/roiw. 12190

Danner, D., D. Snowdon and W. Friesen 2001. Positive emotions in early life and longevity: Findings from the nun study. Journal of Personality and Social Psychology 80: 804-813. https://psycnet.apa.org/doi/10.1037/0022-3514.80.5.804

Diener, E. 2006. Guidelines for national indicators of subjective well-being and ill-being. Journal of Happiness Studies 7: 397-404. https://psycnet.apa.org/doi/10.1007/s10902006-9000-y

Eurostat 2012a. EU-SILC module on well-being. Assessment of the implementation.

Eurostat 2012b. EU-SILC 2013 module on well-being - description of SILC secondary target variables. Version 5 March 2012.

Gove, W. R., C. B. Style and M. Hughes 1990. The effect of marriage on the well-being of adults. A theoretical analysis. Journal of Family Issues 11: 4-35. https://doi.org/10.1177\% 2F019251390011001002

Graham, C. and J. Ruiz Pozuelo 2017. Happiness, stress, and age: How the U-curve varies across people and places. Journal of Population Economics 30: 225-264. https://doi.org/ 10.1007/s00148-016-0611-2

Guven, C., C. Senik and H. Stichnoth 2012. You can't be happier than your wife. Happiness gaps and divorce. Journal of Economic Behavior E Organization 82: 110-130. https: //doi.org/10.1016/j.jebo.2012.01.003

Helmer, C., D. Damon and L. Letenneur 1999. Marital status and risk of Alzheimer's disease. Neurology 53: 1953-1958. https://doi.org/10.1212/WNL.53.9.1953

Helliwell, J., H. Huang, M. Norton and S. Wang 2019. Happiness at different ages: The social context matters. In The economics of happiness: How the Easterlin paradox transformed our understanding of well-being and progress, ed M. Rojas, 455-481. New York: Springer. https://doi.org/10.1007/978-3-030-15835-4_20

Jebb, A., M. Morrison, L. Tay and E. Diener 2020. Subjective well-being around the world: Trends and predictors across the life span. Psychological Science 31: 293-305. https: //doi.org/10.1177\%2F0956797619898826

Kassenböhmer, S. C. and J. Haisken-DeNew 2012. Heresy or enlightenment? The well-being age U-shape effect is flat. Economics Letters 117: 235-238. https://doi.org/10.1016/j. econlet.2012.05.013

Kohler, H., J. Behrman and A. Skytthe 2005. Partner + children = happiness? The effects of partnerships and fertility on well-being. Population and Development Review 31(3): 407-445. https://doi.org/10.1111/j.1728-4457.2005.00078.x 
Kravdal, O., E. Grundy and K. Keenan 2018. The increasing mortality advantage of the married: The role played by education. Demographic Research 38: 471-512. https://doi. org/10.4054/DemRes.2018.38.20

Mikucka, M. 2016. The life satisfaction advantage of being married and gender specialization. Journal of Marriage and Family 78: 759-779. https://doi.org/10.1111/jomf.12290

Nolen-Hoeksema, S. and C. L. Rusting 1999. Gender differences in well-being. In Well-being: The foundations of hedonic psychology, eds D. Kahneman, E. Diener and N. Schwartz. New York: Russell Sage Foundation.

Stutzer, A. and B. S. Frey 2006. Does marriage make people happy, or do happy people get married? Journal of Socio-Economics 35: 326-347. https://doi.org/10.1016/j.socec.2005. 11.043

Verbakel, E. 2012. Subjective well-being by partnership status and its dependence on the normative climate. European Journal of Population/Revue Européenne de Démographie 28: 205-232. https://doi.org/10.1007/s10680-012-9257-2

Wilson, C. M. and A. J. Oswald 2005. How does marriage affect physical and psychological health? A survey of the longitudinal evidence. IZA Discussion Papers 1619, Institute of Labor Economics (IZA). http://ftp.iza.org/dp1619.pdf 


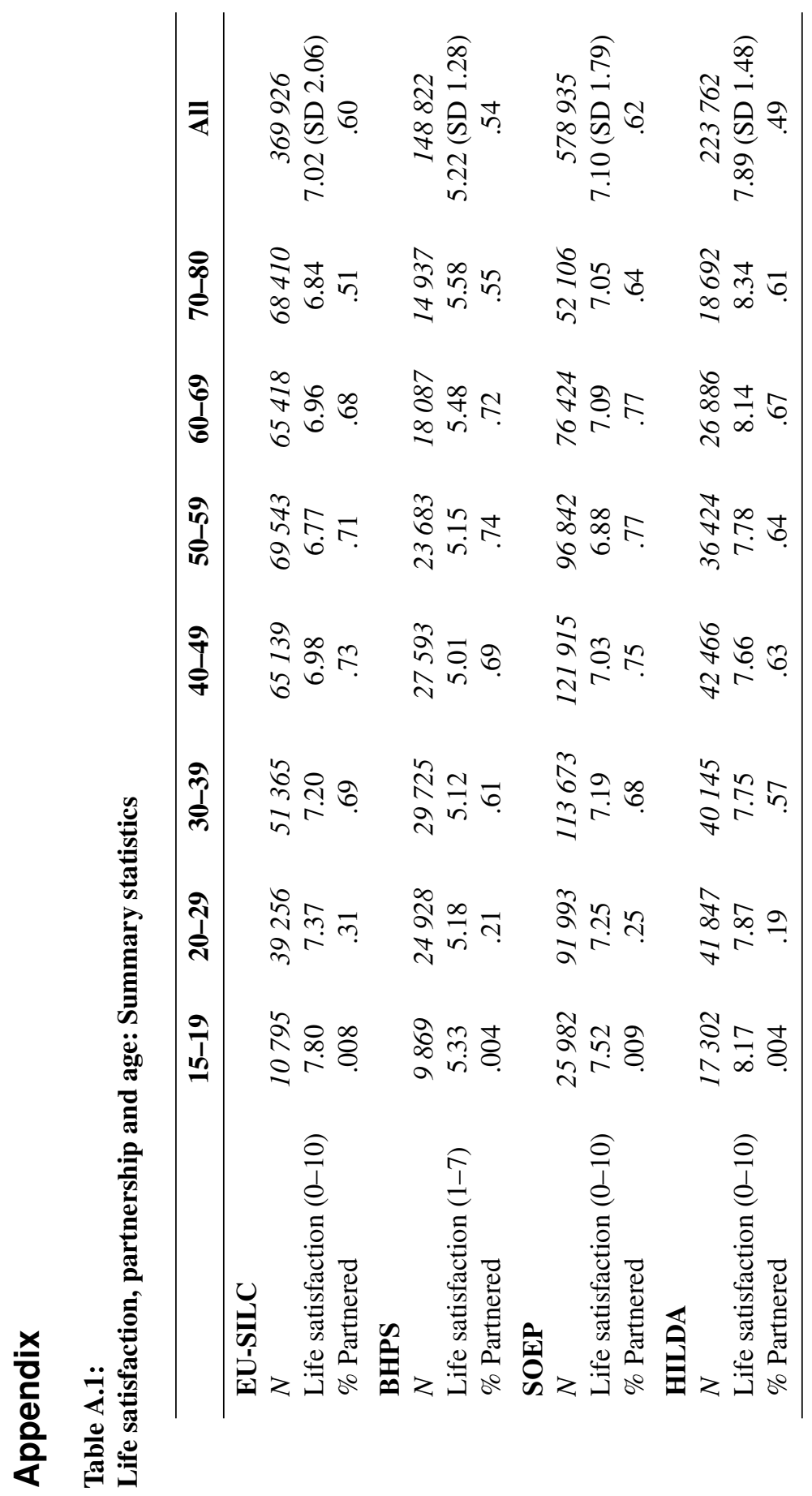


Figure A.1:

The life satisfaction of individuals who move into a partnership

BHPS. NP to P. LS level

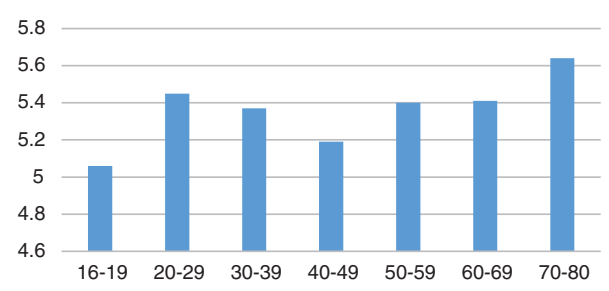

SOEP. NP to P. LS level

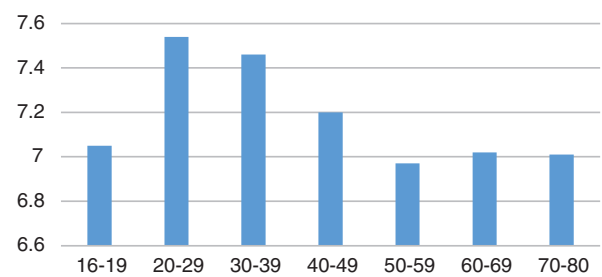

HILDA. NP to P. LS level

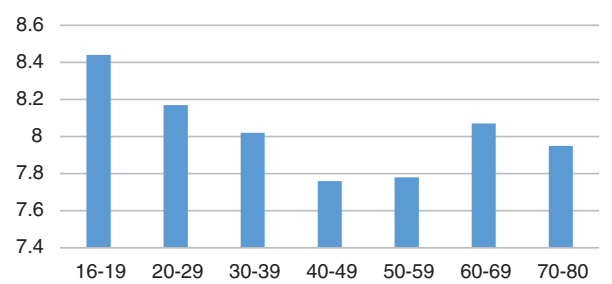

BHPS. NP to P. Change in LS

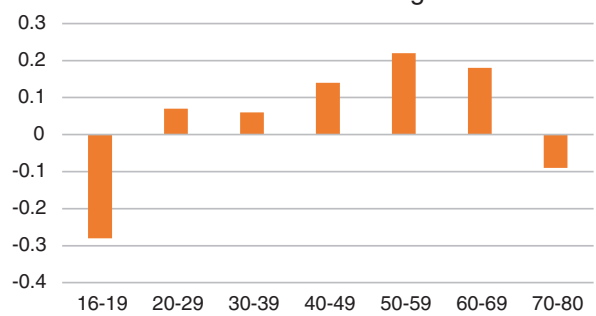

SOEP. NP to P. Change in LS

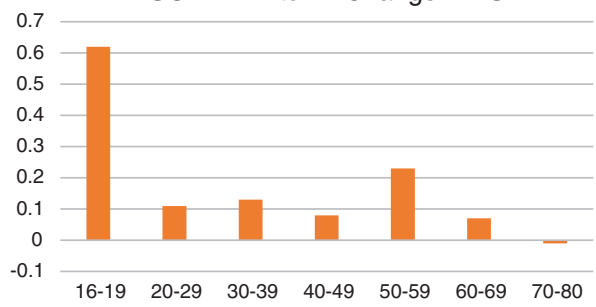

HILDA. NP to P. Change in LS

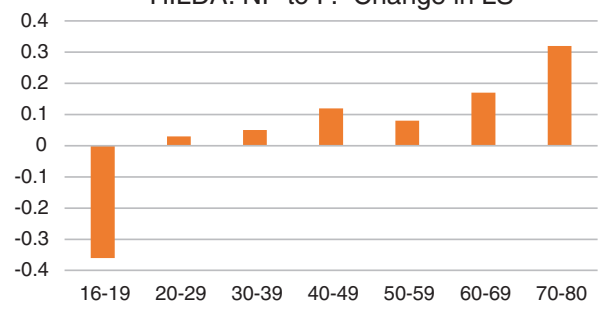


Figure A.2:

The life satisfaction of individuals who move out of a partnership

BHPS. P to NP. LS level

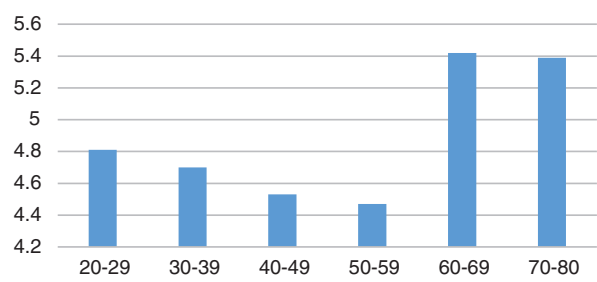

SOEP. P to NP. LS level

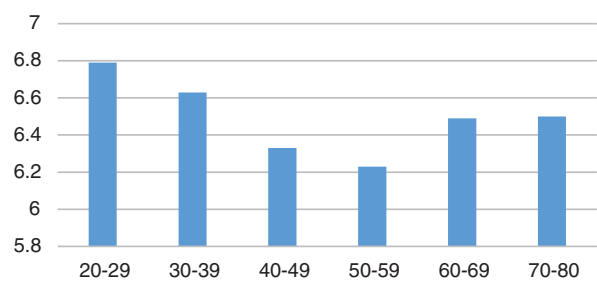

HILDA. P to NP. LS level

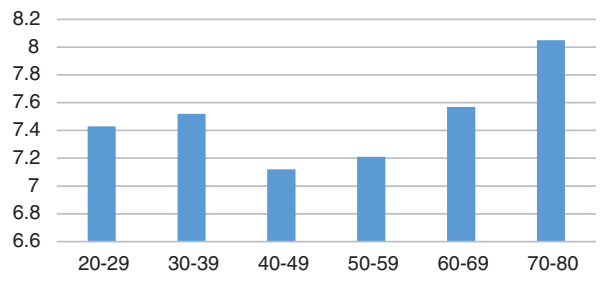

BHPS. P to NP. Change in LS

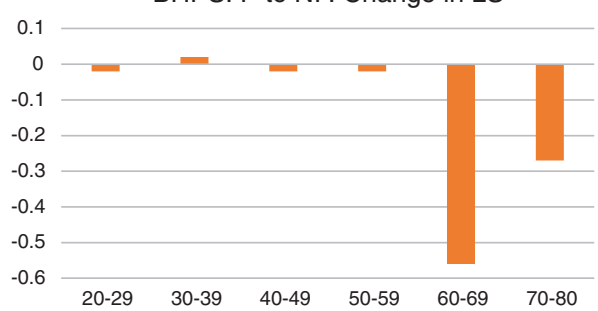

SOEP. $\mathrm{P}$ to NP. Change in LS

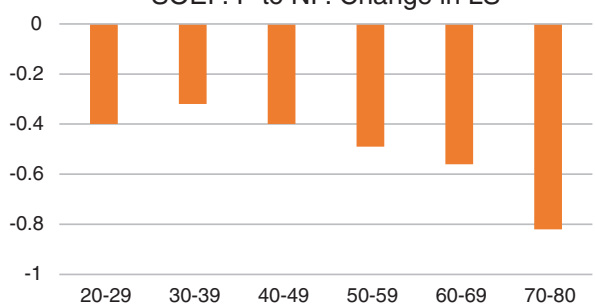

HILDA. P to NP. Change in LS

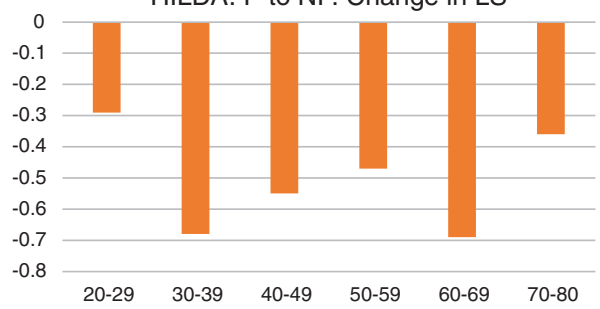

Open Access This article is published under the terms of the Creative Commons Attribution 4.0 International License (https://creativecommons.org/licenses/by/4.0/) that allows the sharing, use and adaptation in any medium, provided that the user gives appropriate credit, provides a link to the license, and indicates if changes were made. 